\title{
Fabrication of Ti10Fe5Si5Cr3Nb Composite Coatings on Ti-6Al-4V Alloy using Laser Cladding Technique
}

\author{
N. Malatji ${ }^{a^{*}}$ (1), A.P.I. Popoola ${ }^{a}$, S. Pityana ${ }^{b}$, T. Lengopeng ${ }^{b}$ \\ ${ }^{a}$ Tshwane University of Technology, Pretoria, South Africa. \\ ${ }^{b}$ Council for Scientific and Industrial Research, Pretoria, South Africa.
}

Received: February 6, 2021; Revised: June 16, 2021; Accepted: June 24, 2021

\begin{abstract}
Ti10Fe $5 \mathrm{Si} 5 \mathrm{Cr} 3 \mathrm{Nb}$ composite coatings were fabricated using laser cladding technique. Laser power was varied from $800 \mathrm{~W}$ to $1200 \mathrm{~W}$ while the scanning speed was kept constant at $1.5 \mathrm{~m} / \mathrm{min}$. The microstructural analysis of the samples was conducted by using optical microscope, $\mathrm{X}$-ray diffractometer and scanning electron microscope coupled with energy dispersive spectroscopy. Potentiodynamic polarization and diamond indenter were used to study the corrosion and microhardness properties of the alloy. The alloy exhibited a dendritic microstructure with Si-rich dispersed phase. Grain coarsening was observed to be dependent on coating depth. The microhardness was high at the top and decreased with coating depth. No improvement in corrosion resistance was noticed but the presence of $\mathrm{Cr}$ in the alloy promoted passivation.
\end{abstract}

Keywords: Laser metal deposition, substrate heating, composite coating, microstructure, microhardness.

\section{Introduction}

Titanium alloy (Ti-6Al-4V) continue to find considerable interest in automotive, aerospace and biomedical applications as a construction material for fabrication of structural components/ parts. This is due to its low density, high mechanical strength, biocompatibility and excellent corrosion resistance $e^{1-3}$. However, its poor surface hardness and wear properties limit its use in more demanding structural applications $\mathrm{s}^{4}$ Therefore, surface modification remains key for improvement of surface properties of this alloy. These properties can be enhanced by various surface modification techniques such as laser cladding, physical and chemical vapour deposition, plasma spraying, carburizing and nitriding ${ }^{5-8}$. Among these technologies, laser cladding is considered the most effective since itproduces coatings with refined microstructures, good metallurgical bonding and improved mechanical properties ${ }^{9,10}$. The stability of these coatings make them enjoy a variety of use in applications where good structural integrity is most desirable. However, the high thermal gradients associated with laser cladding generates residual stresses which may compromise the structural soundness of the coatings during service. These stresses cause formation of microcracks which may serve as initiation sites for failure ${ }^{11-13}$.

The amount and nature of cracks formed may also be determined by the composition of the coating material. The presence of intermetallic phase forming elements such as silicon, aluminium, nickel, chromium etc. in the titanium matrix also reduces the ductility of the alloy ${ }^{14-16}$. Intermetallic phases have different thermal expansion coefficient from the matrix. The difference in thermal coefficient of expansion between the intermetallic phases and the matrix causes stresses to be generated during solidification. Since intermetallic

*e-mail:doublen.malatji@gmail.com compounds are more brittle than the matrix, they become initiation sites for propagation of cracks (cracks form or around the phases) ${ }^{17}$. These phases may also be un-wetted and weaken their bond with the matrix ${ }^{18}$. Therefore, the combination of high solidification rates and formation of intermetallic phases exarcebates formation of cracks. Titanium and aluminium silicides were reported to form when silicon was incorporated into a titanium alumnide alloy. The alloys with high Si content and fabricated at high laser scanning speeds were associated with high amount of intermetallic phases and cracks $^{19}$. Dai et al. ${ }^{20}$ reported similar results when $\mathrm{Si}$ was incorporated into Ti-Al alloy. The presence of $\mathrm{Ti}_{5} \mathrm{Si}_{3}$ phase was found to improve the hardness of the Ti-Al coatings from $600 \mathrm{HV}$ to $900 \mathrm{HV}$ but formation of cracks could not be avoided at all silicon content.

To reduce generation of thermal stresses and improve the ductillity of the laser cladded coatings, variation of laser process parameters have proved critical to aid in prodduction of crack free coatings. However, Ti coatings with intermetallic phases inducers tend to be difficult to fabricate even when process parameters are varied ${ }^{21,22}$. Therefore, in situ substrate heating during laser has been adopted and was found to be effective in lowering thermal gradients and promote slow cooling rates. This method do not only eliminate formation of cracks but also induce grain growth and improve ductility of the coatings ${ }^{23,24}$. Crack free TiVCrAlSi coatings were successfully produced when Ti-6Al-4V substrate was heated to $450^{\circ} \mathrm{C}$ during cladding. Slow solidification rates induced by the heating of the substrate promoted precipitation of silicide intermetallic phases but had no adverse effect on the quality of the coatings ${ }^{25}$. Tao et al ${ }^{6}$ also produced crack free $\mathrm{TiNi} / \mathrm{Ti}_{2} \mathrm{Ni}$ composite coatings when the substrate was preheated. However, heating the substrate at temperatures 
higher than $600^{\circ} \mathrm{C}$ increased the diffusion of aluminium and titanium from the substrate into the coating. Even though many researchers report of variation of laser process parameters during synthesis of titanium alloys and coatings in literature, limited investigations have been conducted on in sutu heating of substrate during deposition of these materials. Few studies on synergetic effect of variation of laser process parameters and in situ heat treatment of the substrate during laser depostion are also scarce. Therefore, in this work, Ti10Fe $5 \mathrm{Si} 5 \mathrm{Cr} 3 \mathrm{Nb}$ composite coatings were successfully produced on Ti-6Al-4V alloy by laser cladding at circumstance temperature of $450^{\circ} \mathrm{C}$. The microstructural, corrosion and hardness characteristics of the coatings were investigated.

\section{Experimental}

Pure commercial elemental powders of $\mathrm{Ti}, \mathrm{Fe}, \mathrm{Si}, \mathrm{Cr}$ and $\mathrm{Nb}$ with a size range of between 45 to $90 \mu \mathrm{m}$ were mixed in a tubular mixer for 24 hours and used as precursor powder for production of Ti10Fe $5 \mathrm{Si} 5 \mathrm{Cr} 3 \mathrm{Nb}$ alloy using laser metal deposition. An IPG Yb laser was used and the laser processing parameters are shown in Table 1. The alloy powder was deposited on a Ti-6Al-4V substrate and the argon carrier gas was used during deposition to reduce oxidation. The microstructural and phase characteristics of the coatings were examined using scanning electron microscope equipped with energy dispersive spectroscopy and x-ray diffractometer. The EDS mapping was used to study the distribution of the elements in the alloy. The microhardness of the coatings was measured using diamond indenter with dwell time of 10 s and load of 500 gf. Minimum of 10 measurements were made on the cross section of the samples and averaged to obtain accurate values. Potentiodynamic polarization was used to characterize the corrosion performance of the samples in $0.5 \mathrm{M} / \mathrm{L} \mathrm{H}_{2} \mathrm{SO}_{4}$ solution. The polarization measurements were carried from a potential of -1.5 to $1.5 \mathrm{~V}$ with a scanning rate of $0.01 \mathrm{~V} / \mathrm{s}$. Saturated calomel electrode was used as a reference and platinum served as a counter electrode. The HEA samples were used as working electrode with an exposed area of $1 \mathrm{~cm}^{2}$. Nova 1.8 was used to extrapolate the corrosion parameters obtained from the Tafel curves.

\section{Results and Discussion}

\subsection{Microstructural characteristics}

Figure 1 shows the stereo microscope macrographs of samples fabricated at different laser power. The samples revealed no visibility of macrocracks and the change in power had no massive effect on the thickness of the coatings. The absence of these cracks may be due to slow cooling rates induced by heating the substrate during cladding. The heating of the substrate reduces the thermal gradient and minimizes residual stresses in the coatings ${ }^{25,26}$. However, the deformation of the deposits was more evident in higher laser power. High laser power is associated with high energy density and promotes increased melting of particles. However, the high temperature induced by high laser power changes melt pool flow dynamics and lead to structural deformation of the resulting deposits ${ }^{27}$.
Table 1. Sample codes and laser processing parameters

\begin{tabular}{ccc}
\hline Sample Code & Laser Power $(\mathbf{W})$ & $\begin{array}{c}\text { Scanning speed } \\
(\mathbf{m} / \mathbf{m i n})\end{array}$ \\
\hline TA-800 & 800 & 1.5 \\
\hline TA-1000 & 1000 & 1.5 \\
\hline TA-1200 & 1200 & 1.5 \\
\hline
\end{tabular}
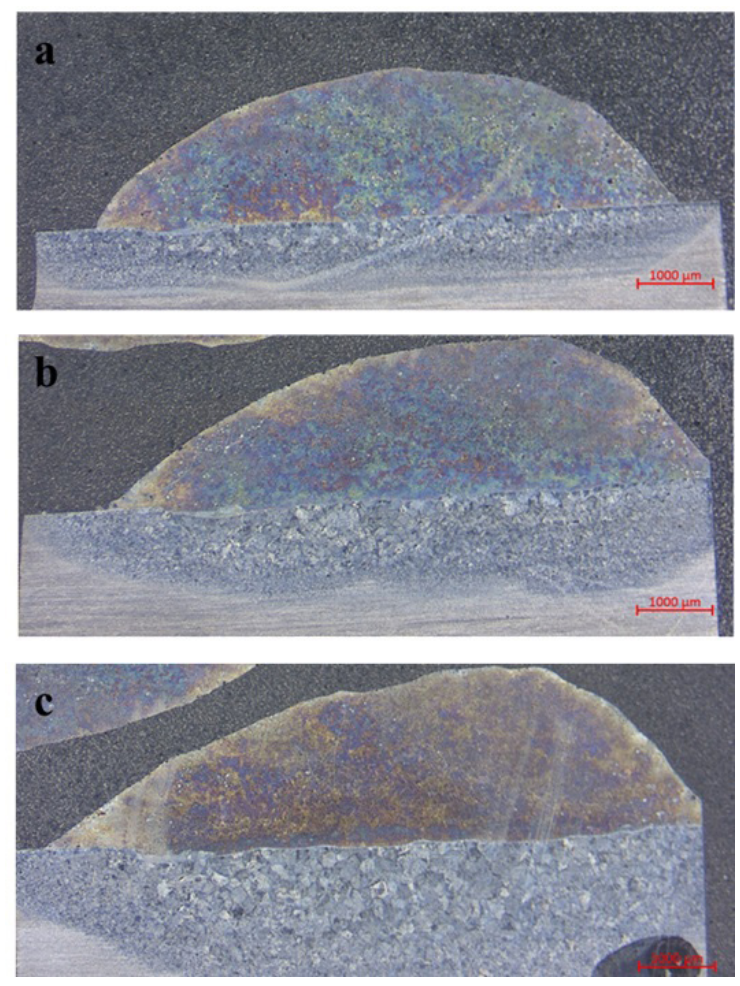

Figure 1. Stereo Microscope Images for samples fabricated at laser power of (a) $800 \mathrm{~W}$, (b) $1000 \mathrm{~W}$ and (c) $1200 \mathrm{~W}$.

Figure 2 shows the optical microscope micrographs (top, middle and bottom sections) of the Ti10Fe $5 \mathrm{Si} 5 \mathrm{Cr} 3 \mathrm{Nb}$ coatings fabricated at different laser powers. It can be seen from the figure that the top, middle and bottom regions of the coatings exhibit different microstructures. The top region is characterized by a dendritic microstructure with finer grains. The middle region shows a similar microstructure but with coarser and aquiaxed grains. On the other hand, columnar and elongated grains are most evident in the bottom section of the coatings. This behavior in the microstructural evolution signifies the nature and direction of cooling in the different regions of the coatings. High solidification rates are dominant at the top region of the coatings and decreases towards the bottom. This direction in solidification also determine the size of the grains that are formed ${ }^{19}$. It can also be observed from the figure that varying the laser power from 800 to $1200 \mathrm{~W}$ had significant effect on the grain growth of the coatings. The coarseness of grains increases with increase in laser power. The presence of unmelted particles also follow the trend of microstructural evolution. The amount of unmelted particles reduces as function of coatings depth 

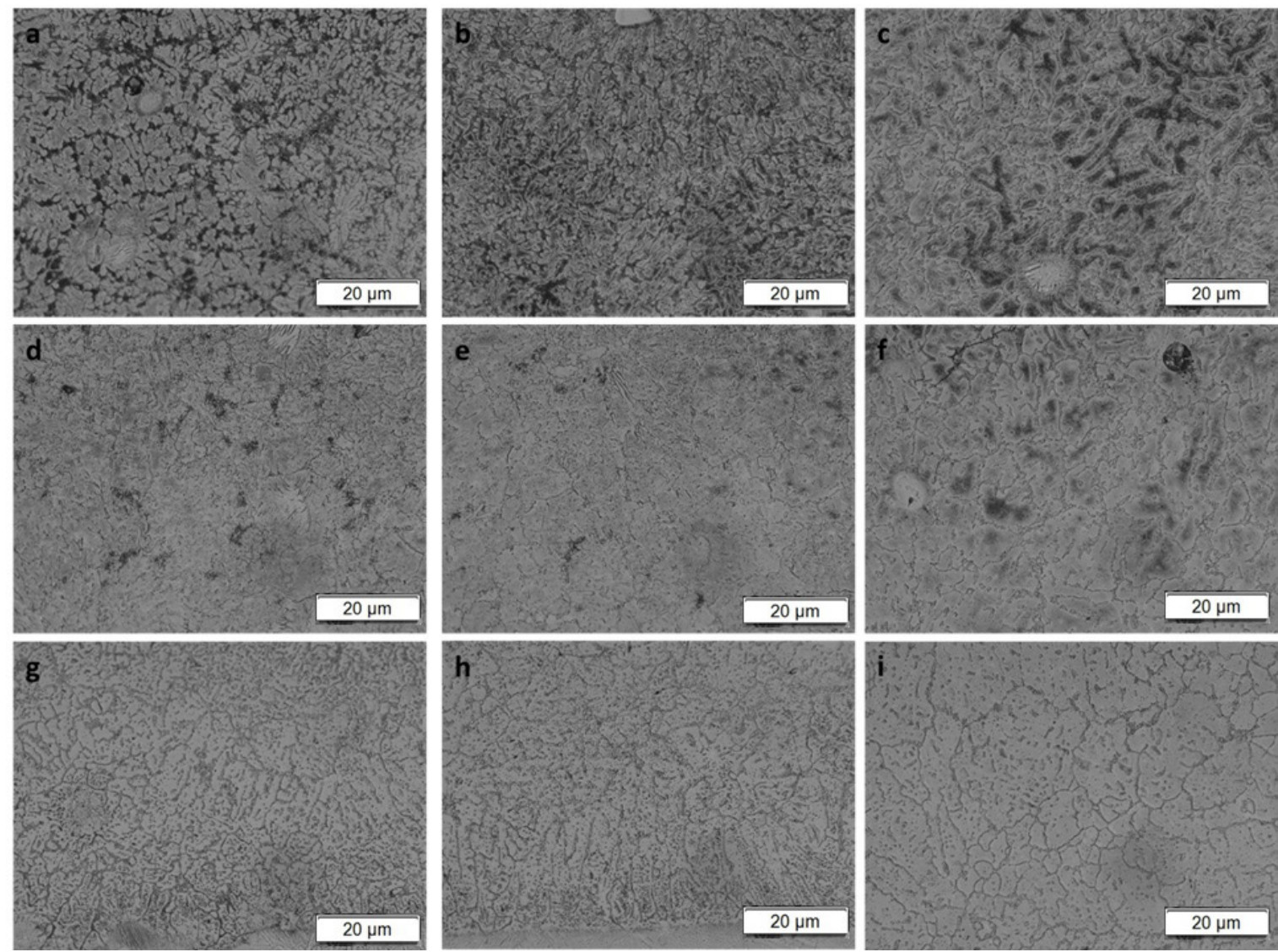

Figure 2. Optical microscope micrographs of Ti-Si-Fe-Cr-Nb alloy fabricated at $800 \mathrm{~W}$ (a, d and g: top, middle and bottom layers), $1000 \mathrm{~W}$ (b, e and h: top, middle and bottom layers) and $1200 \mathrm{~W}$ (c, f and i: top, middle and bottom layers).

and increment in laser power. The increment in laser power increases laser energy density. High laser power densities are associated with high temperatures in the melt pool which lead increased melting of particles and create inducive environment for grain growth ${ }^{28}$.

Figure 3 reveals the SEM images that were taken from the top, middle and bottom part of the coatings. The microstructure is characterized by precipitated phase that is dispersed in a continuous matrix. The dispersion and size of the phase differ with the depth of the coating and laser power. The amount of the dispersed phase reduces with coating depth and laser power. However, the size of the dispersed phase shows an opposite behavior dispersion of the phase. Dissolution of the dispersed phase is also evident and it is subject to the same conditions as its growth. These results support the findings obtained from the optical microscope micrographs. According to EDS results shown in Table 1, the matrix $(\mathrm{Y})$ is titanium based while the dispersed phase $(\mathrm{X})$ is rich in silicon.

Distribution of elements in the coatings is shown in Figure 4 and Table 2. Uniform distribution of elements is evident in all the coatings as depicted in the EDS elemental maps. The maps also show that silicon distribution is higher in the dispersed phase than in the matrix.

The amount of all the elements is similar in all regions of the coating and no diffusion of $\mathrm{Ti}$ and $\mathrm{Al}$ from the substrate was observed. The uniform distribution of elements in the coating shows that proper mixing was achieved and that no segregation occurred during cladding. Figure 5 shows the XRD pattern of Ti10Fe $5 \mathrm{Si} 5 \mathrm{Cr} 3 \mathrm{Nb}$ composite coating obtained using laser power of $800 \mathrm{~W}$. Phase analysis revealed the existence of $\beta$-Ti as a major phase while $\mathrm{TiFe}$ and $\mathrm{Ti}_{3} \mathrm{Si}_{5}$ were identified as precipitate phases. These results are similar to those reported by other authors. Titanium matrix doped with $\mathrm{Fe}, \mathrm{Nb}$ and $\mathrm{Cr}$ yielded alloys which were mainly characterized by $\beta$ phase $\mathrm{e}^{29-32}$.

\subsection{Microhardness}

Figure 6a shows the microhardness profile of the coatings fabricated at different laser powers. The coatings obtained from all laser processing parameters yielded improved microhardness values higher than that of the substrate. The microhardness values of the alloy deposits were all in excess of $570 \mathrm{HV}$. The values obtained are almost double of the one exhibited by the substrate. The higher microhardness values displayed by the coatings can be attributed to several factors: (i) the high solidification rates associated with laser cladding causes rapid nucleation and results in microstructure with fine grains. Such microstructures have high density of grain boundaries which reduces the motion of dislocations and improves the resistance of the coatings to deformation ${ }^{14}$. (ii) The $\beta$-Ti matrix is associated with high mechanical 

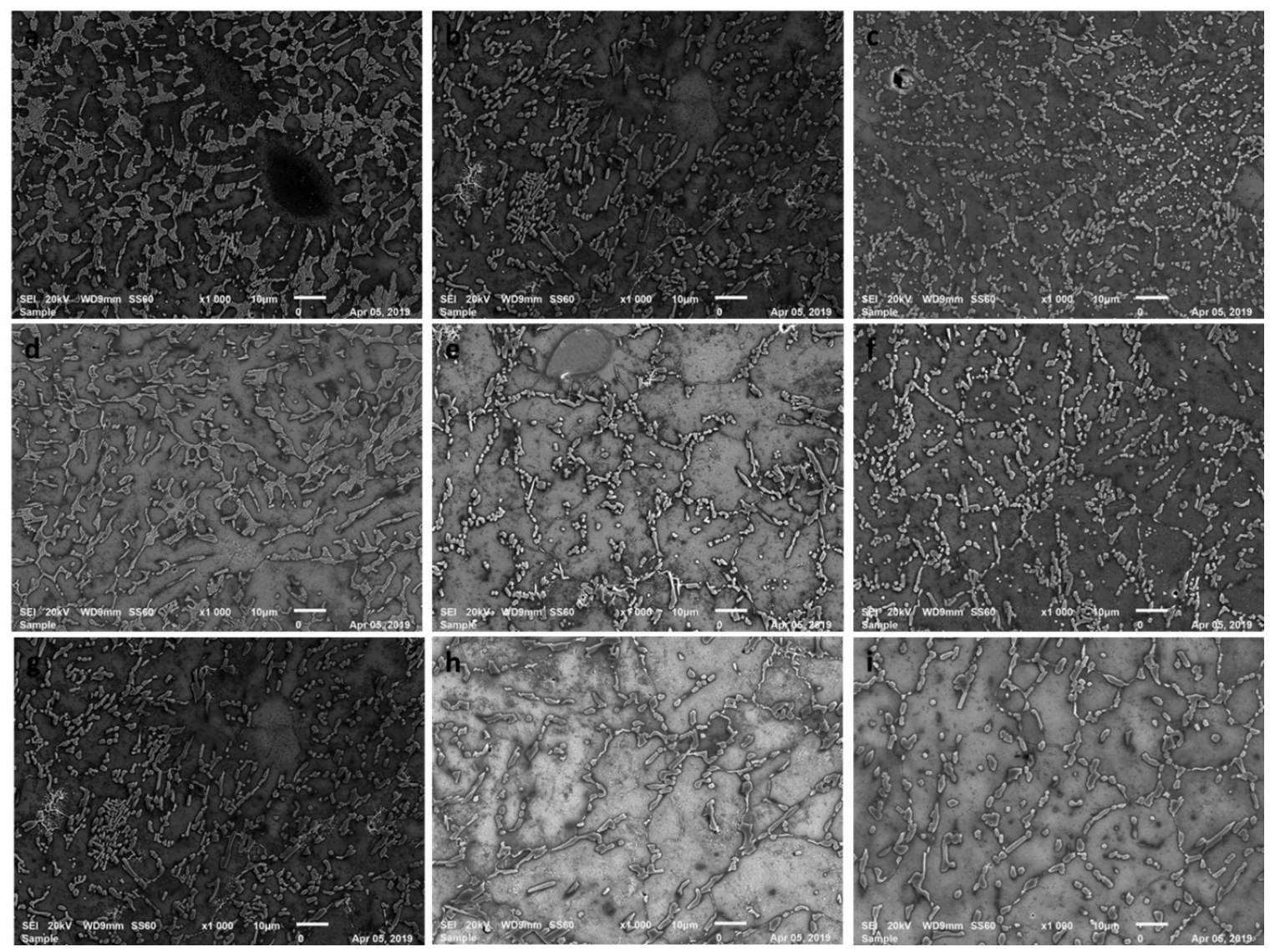

Figure 3. Scanning electron microscope images of Ti-Si-Fe-Cr-Nb alloy fabricated at $800 \mathrm{~W}$ (a-c: top, middle and bottom layers), $1000 \mathrm{~W}$ (d-f: top, middle and bottom layers) and 1200W (g-i: top, middle and bottom layers).

Table 2. EDS results.

\begin{tabular}{|c|c|c|c|c|c|}
\hline Sample Name & $\mathrm{Ti}$ & $\mathrm{Si}$ & $\mathrm{Fe}$ & $\mathrm{Cr}$ & $\mathrm{Nb}$ \\
\hline \multicolumn{6}{|c|}{ TA- 800} \\
\hline Top & 78.7 & 5.31 & 8.34 & 5.06 & 2.59 \\
\hline Middle & 75.74 & 6.98 & 8.88 & 5.27 & 3.13 \\
\hline Bottom & 77.49 & 5.48 & 9.13 & 4.92 & 2.98 \\
\hline \multicolumn{6}{|c|}{ TA-1000 } \\
\hline Top & 76.21 & 5.65 & 8.7 & 5.43 & 4.01 \\
\hline Middle & 77.04 & 5.13 & 8.1 & 5.61 & 4.12 \\
\hline Bottom & 76.55 & 6.5 & 8.9 & 4.83 & 3.21 \\
\hline \multicolumn{6}{|c|}{ TA-1200 } \\
\hline Top & 74.58 & 5.76 & 8.53 & 5.71 & 4.8 \\
\hline Middle & 77.39 & 4.81 & 7.81 & 5.35 & 4.64 \\
\hline Bottom & 78.14 & 5.22 & 8.09 & 4.67 & 3.88 \\
\hline Phase X & 72.69 & 11.33 & 7.87 & 4.95 & 3.16 \\
\hline Phase Y & 78.17 & 1.81 & 10.16 & 6.52 & 3.33 \\
\hline
\end{tabular}

strength and hardness ${ }^{30}$. (iii) Precipitation of intermetallic phases $\left(\mathrm{Ti}_{3} \mathrm{Si}_{5}\right.$ and $\left.\mathrm{TiFe}\right)$ occurs along the grain boundaries and causes crystallographic misalignment that makes the movement of dislocations difficult ${ }^{19}$. The microhardness is found to be dependent on coating depth and no significant effect on variation of laser power was noticed. The difference in microhardness for all the laser power used was an average of $15 \mathrm{HV}$. Highest microhardness value of $665 \mathrm{HV}$ was obtained at coating depth of $200 \mu \mathrm{m}$ for the sample fabricated $800 \mathrm{~W}$. The value decreased to $523 \mathrm{HV}$ at a depth 

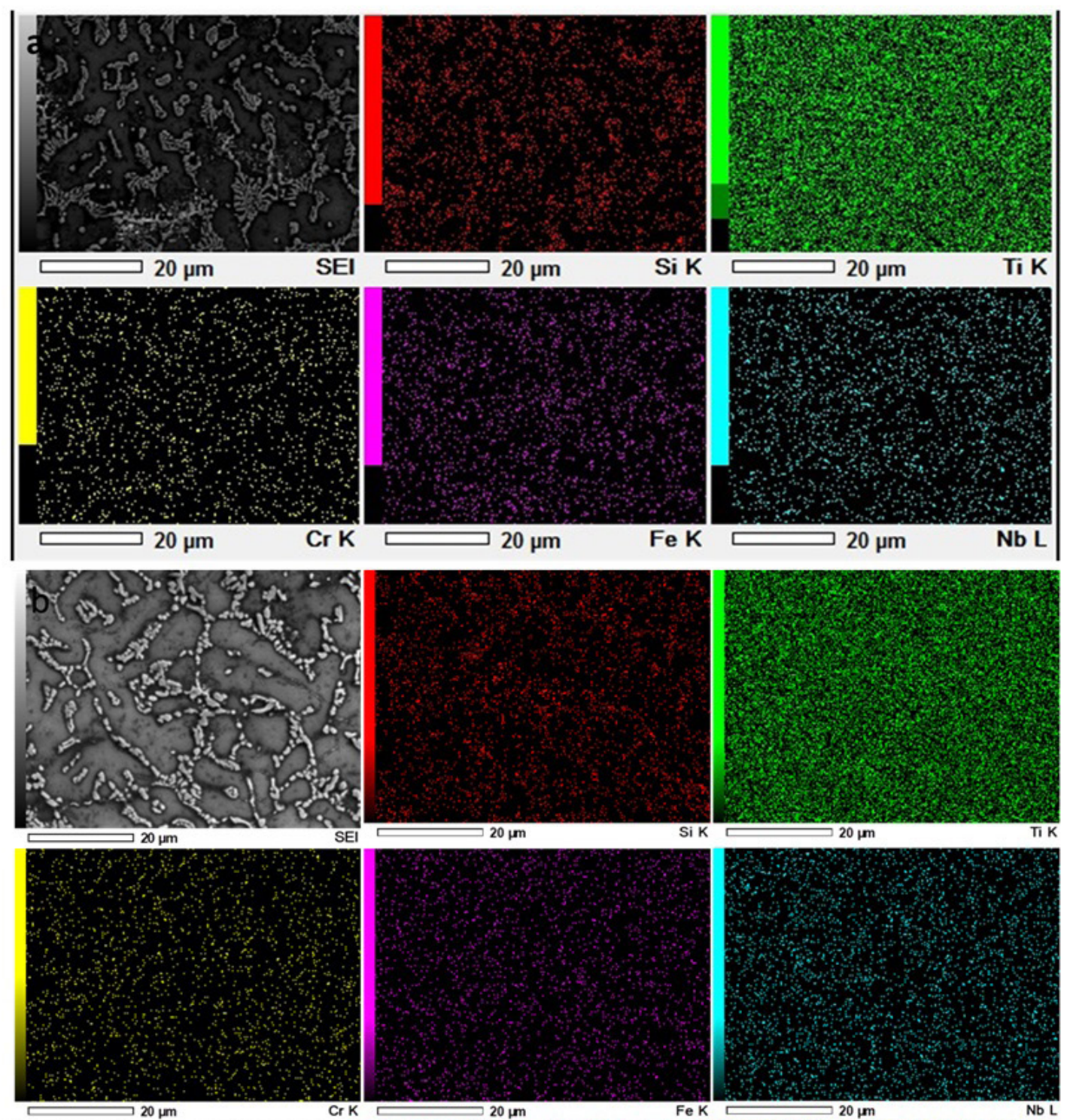

Si K

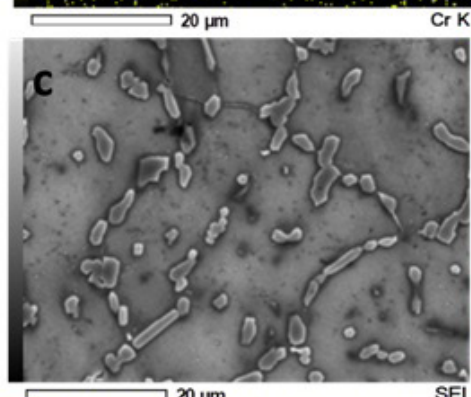

Fe K
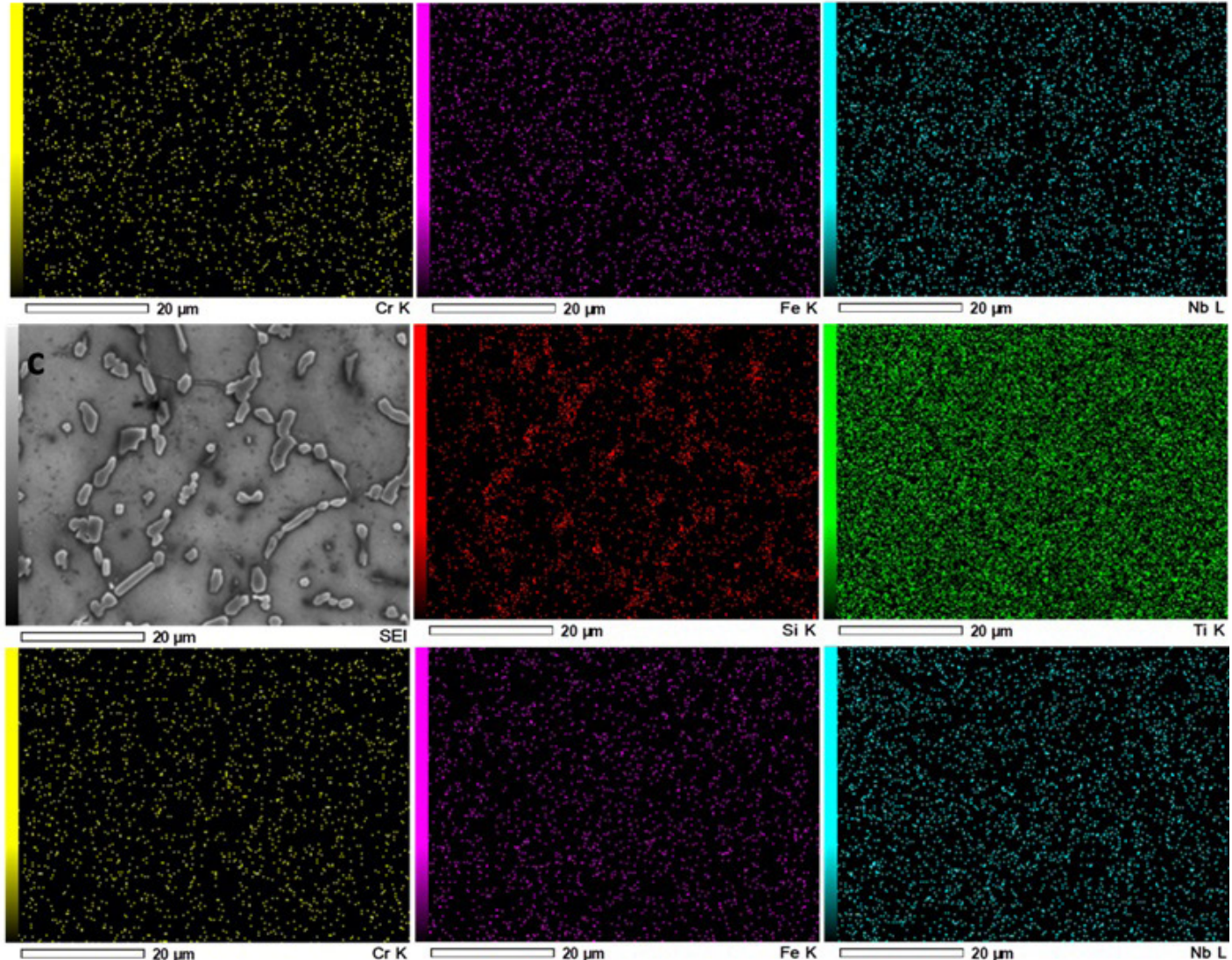

Si K

Ti K

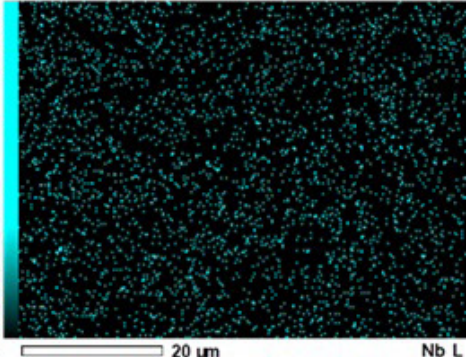

Figure 4. Elemental Mapping. 
of $1800 \mu \mathrm{m}$ for the same sample. These results correspond with the optical micrographs shown in Figure 1, where grain coarsening proved to be subject to coating depth. The reduction in solidification rate of the coating from the top to bottom region induces grain coarsening and reduces microhardness property ${ }^{25}$.

\subsection{Electrochemical characteristics}

Pontentiodynamic polarization of Ti-6Al-4V alloy, TA-800, TA-1000 and TA-1200 composite coatings are presented in Figure 7. The samples were tested in a solution containing $0.5 \mathrm{M}$ of sulphuric acid in room temperature. The figure reveals that Ti-6Al-4V alloy possessed the lowest corrosion potential $(-483 \mathrm{mV})$ and current density $\left(4.3 \times 10^{-6} \mathrm{~A} / \mathrm{cm}^{2}\right)$ as compared to the composite coating prepared at different laser power. Despite the low corrosion potential displayed by the substrate, the difference is very low when it is compared to the potential shown by the coatings. Since the electrochemical theory states that materials with low current density are associated with better corrosion resistance, it can be concluded that the substrate possess

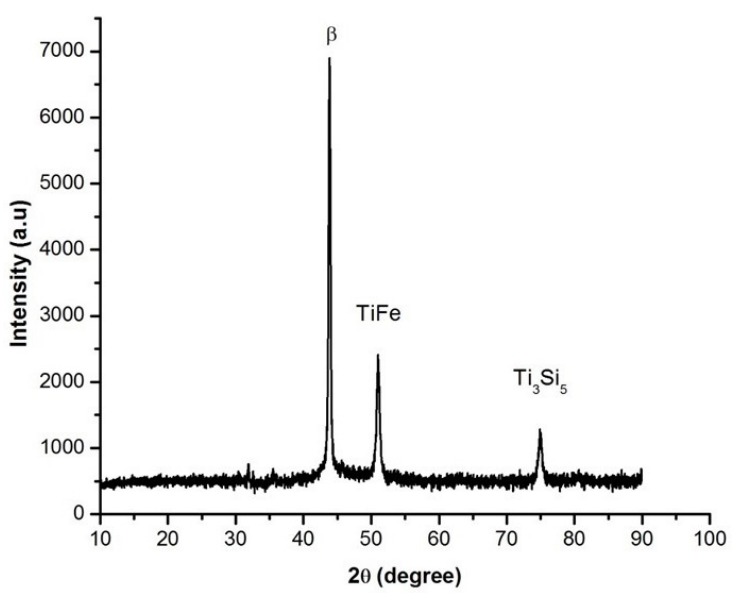

Figure 5. XRD pattern for Ti10Fe $5 \mathrm{Si} 5 \mathrm{Cr} 3 \mathrm{Nb}$ coating obtained at laser power of $800 \mathrm{~W}$. enhanced anti-corrosive properties than the coatings ${ }^{18}$. The alloy had a wider passive region in a anodic branch than the composite coating showing that it has higher potential to form a protective film. However, current fluctuation was observed in this region and suggest that the protective layer formed is not stable. According to Nabhani et al..$^{33}$, vanadium and its oxide phase decrease the resistance of this alloy to corrosion attack. Vanadium phase increase the number of vacancies in the oxide layer and allows more penetration of corrosive species. Corrosion potential and current density of $-487 \mathrm{mV}$ and $2.075 \times 10^{-5} \mathrm{~A} / \mathrm{cm}^{2}$, respectively, were obtained for the alloy (TA-800) fabricated at laser power of $800 \mathrm{~W}$. The increase of the laser power from $800 \mathrm{~W}$ to $1000 \mathrm{~W}$ caused a negative shift in potential from $-487 \mathrm{mV}$ to $-500 \mathrm{mV}$. The current density was also increased from $2.075 \times 10^{-5} \mathrm{~A} / \mathrm{cm}^{2}$ to $4.3 \times 10^{-6} \mathrm{~A} / \mathrm{cm}^{2}$. However, further increase in laser power from $1000 \mathrm{~W}$ to $1200 \mathrm{~W}$ yielded results that were similar to those obtained in TA-800. TA-1200 had the highest corrosion potential $(-484 \mathrm{mV})$ but the current density $\left(3.94 \times 10^{-5} \mathrm{~A} / \mathrm{cm}^{2}\right)$ was lower than that of TA-800. Even though TA-1200 had the highest corrosion potential than TA-800, a difference of $3 \mathrm{mV}$ in potential is negligible. A clear evidence of passivation is noticeable on all of the curves of the samples. There is stable increase in current density in the anodic branch from a potential of around $-462 \mathrm{mV}$ to $-284 \mathrm{mV}$ for all the samples which shows that transformation from active to near passive state is achieved in this potential range. The samples re-enter an active state for a short potential range and then passivate again. The presence of $\mathrm{Cr}$ in the alloy can be attributed for the good passivation displayed. According to Jiang et al..$^{34}$ chromium forms a thin and compact film that hinder further interaction between the corrosive media with the surface of the alloy. The passive current density of TA- 800 was also lower than that of TA-1000 and TA-1200. Therefore, from the results that were obtained, it can be deduced that TA- 800 exhibited nobler corrosion characteristics than TA-1000 and TA-1200. However, no relationship between corrosion behavior of the samples with the laser power used to produce them could be established. a

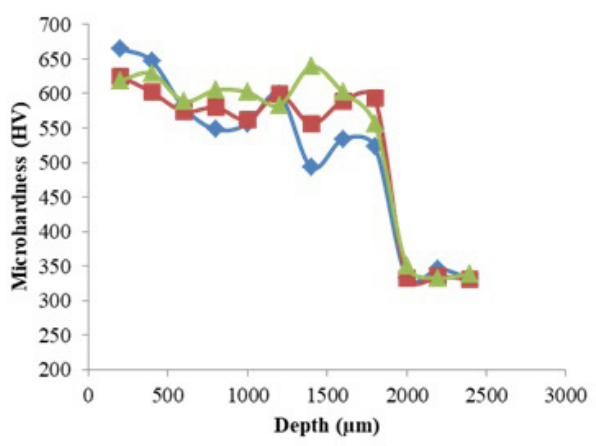

b

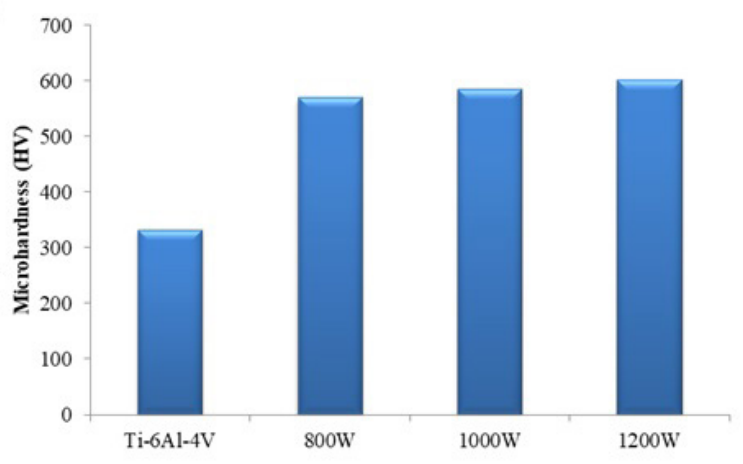

Figure 6. Microhardness of values of Ti10Fe $5 \mathrm{Si} 5 \mathrm{Cr} 3 \mathrm{Nb}$ composite coatings (a) profile and (b) average. 


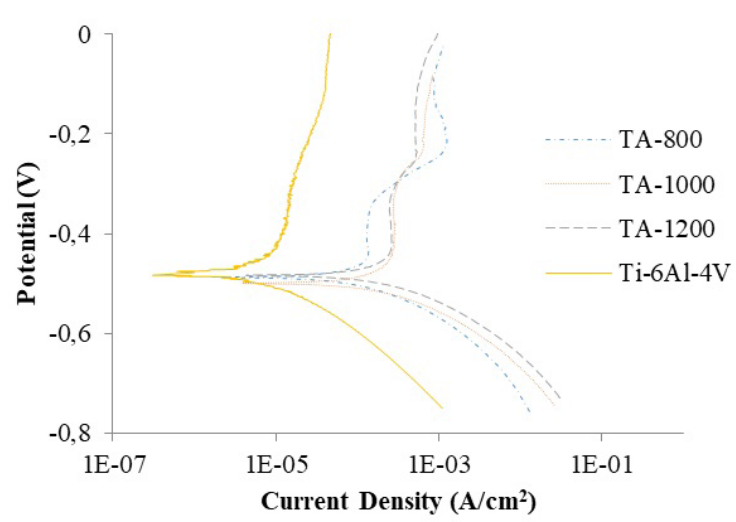

Figure 7. Polarization curves.

\section{Conclusion}

Ti composite coating was successfully produced using laser cladding on Ti-6Al-4V substrate. The heating of the substrate during cladding minimized residual stresses and enabled formation of crack free coating. Partially melted particles were observed at samples produced at laser power of $800 \mathrm{~W}$ and disappeared with the rise in energy density. However, deformation in structure of the coating occurred as a result of increasing laser power. The predominant phase was determined to be $\beta$-Ti and precipitates of titanium silicide was found to be dispersed along the grain boundaries. The formation of the dispersed phase was also found to be subject to the laser power used. The difference in microstructural characteristics on the different regions of the coatings revealed that the solidification rate of the deposit decreases with its depth. At high laser power grain coarsening was induced and varied with coating depth. This corresponded with the hardness profiles that showed decreasing values with respect to coating depth. Despite this, the hardness values of the coating remained higher than those of the substrate. The average microhardness of the composite coating produced at laser power of $1200 \mathrm{~W}$ (603 HV) was almost two times higher than that of Ti-6Al$4 \mathrm{~V}$ alloy $(333 \mathrm{HV})$. The alloy displayed better corrosion resistance than the composite coating. However, there was evidence that the protective film formed on the substrate was prone to pitting while the composite coating oxide was stable. Among the coating fabricated at different laser power, TA-800 exhibited improved electrochemical performance. Nevertheless, no relationship between effect of laser power and electrochemical performance of the coating could be established.

\section{Acknowledgement}

This work is based on the research supported by National Research Foundation of South Africa for the Grant, Unique Grant No. 120622. Research facilities were supported by Tshwane University of Technology and Council for Scientific and Industrial Research.

\section{References}

1. Wang L, Ma H, Fan Q, Yao J, Shen X, Zhang S, et al. Simultaneously enhancing strength and ductility of Ti-6Al-4V alloy with the hierarchical structure via a novel thermal annealing treatment. Mater Charact. 2021;176:111112.

2. Nourollahi A, Razavi RS, Barekat M, Anaraki MV, Erfanmanesh M. Microstructural investigation of direct laser deposition of the Ti-6Al-4V alloy by different melt pool conditions. J Mat Res Technol. 2021;13:590-601.

3. Rabadia CD, Liu Yj, Cao GH, Li YH, Zhang CW, Sercombe $\mathrm{TB}$, et al. High-strength $\beta$ stabilized Ti-Nb-Fe-Cr alloys with large plasticity. Mater Sci Eng A. 2018;732:368-77.

4. Waghmare DT, Pahdee CK, Prasad R, Masanta M. NiTi coating on Ti-6Al-4V alloy by TIG cladding process for improvement of wear resistance: microstructure evolution and mechanical performances. J. Mat. Proc. Tech. 2018;262:551-61.

5. Afonso CRM, Vidilli AI, Spinelli JE, Riva R, Amigo V, Kiminami $\mathrm{CS}$. An assessment of microstructure and properties of laser clad coatings of ultrafine eutectic $\beta$ Ti-Fe-Nb-Sn composite for implants. Surf Coat Tech. 2017;328:161-71.

6. Sitek R, Kaminski J, Borysiuk J, Matysiak H, Kubiak K, Kurzydlowski KJ. Microstructure and properties of titanium alumnides on Ti6A14V titanium alloy produced by chemical vapor deposition method. Inter. 2013;36:36-44.

7. Han J, Zhang D, Chen G, Meng S, Zhang X. Fabrication, microstructure and properties of electron beam-physical vapour deposited TiAl sheet and TiAl/Nb laminated composites. Trans Nonferrous Met Soc China. 2006;16:s449-52.

8. Jaeggi C, Frauchiger V, Eitel F, Stiefel M, Schmotzer H, Siegmann S. The effect of surface alloying of Ti powder for vacuum plasma spraying of open porous titanium coatings. Acta Mater. 2011;59:717-25.

9. Feng Y, Feng K, Yao C, Li Z, Sun J. Microstructure and properties of in-situ synthesized $\left(\mathrm{Ti}_{3} \mathrm{Al}+\mathrm{TiB}\right) / \mathrm{Ti}$ composites by laser cladding. Mater Des. 2018;157:258-72.

10. Wang HM, Liu YF. Microstructure and wear resistance of laser clad $\mathrm{Ti}_{5} \mathrm{Si}_{3} / \mathrm{NiTi}_{2}$ intermetallic composite coating on titanium alloy. Mater Sci Eng A. 2002;338:126-32.

11. Jian LN, Wang HM. Microstructure and wear behaviors of laser-clad $\mathrm{Cr}_{13} \mathrm{Ni}_{5} \mathrm{Si}_{2}$-based metal-silicide coatings on a titanium alloy. Surf Coat Tech. 2005;1992:305-10.

12. Wang C, Dong C. design and laser cladding of Ti-Fe-Zr alloy coatings. Mater. Today Com. 2015;3:43-51.

13. Sun RL, Yang DZ, Guo LX, Dong SL. Microstructure and wear resistance of NiCrBSi laser clad layer on titanium alloy substrate. Surf Coal Technol. 2000;132:251-5.

14. Carcel B, Serrano A, Zambrano J, Amigo V, Carcel AC. Laser cladding of TiAl intermetallic alloy on Ti6Al4V: process optimization and properties. Phy Pro. 2014;56:284-93.

15. Knaislova A, Novak P, Kopecek J, Prusa F. Properties comparison of Ti-Al-Si alloys produced various metallurgy methods. Materials (Basel). 2019;12:3084.

16. de Oliveira Bauer JR, Loguercio AD, Reis A, Rodrigues LE Fo. Microhardness of Ni-Cr alloys under different casting conditions. Braz Oral Res. 2006;20:40-6.

17. Zhao Z, Chen J, Guo S, Tan H, Lin X, Huang W. Influence of $\alpha / \beta$ interface phase on the tensile properties of laser cladding deposited Ti-6Al-4V titamium alloy. J Mater Sci Technol. 2017;33:675-81.

18. Malatji N, Lengopeng T, Pityana S, Popoola API. Microstructural, mechanical and electrochemical properties of $\mathrm{AlCrFeCuNiW}$ high entropy alloys. J Mat Res Tech. 2021;11:1594-603.

19. Majumdar JD, Rittinghaus SK, Wissenbach KW, Hoche D, Blawert C, Weisheit A. Direct laser cladding of the silicide dispersed titanium alumnide (Ti45A15Nb0.5Si) composites. Opt Laser Technol. 2018;106:182-90. 
20. Dai J, Zhang F, Wang A, Yu H, Chen C. Microstructure and properties of Ti-Al coating and Ti-Al-Si system coatings on Ti-6Al-4V fabricated by laser surface alloying. Surf Coat Tech. 2017;309:805-13.

21. Nazari KA, Rahman Rashid RA, Palanisamy S, Xia K, Dargusch MS. A novel Ti-Fe composite coating deposited using laser cladding of low cost recycled nano-crystalline titanium powder. Mater Lett. 2018;229:301-4.

22. Zhou S, Xu Y, Liao B, Sun Y, Dai X. In-situ synthesis of TiFe-based alloys prepared by the combination of mechanical alloying and laser melting deposition: microstructure and corrosion resistance. J Alloys Compd. 2018;768:697-706.

23. Alimardani M, Fallah V, Khajepour A, Toyserkani E. The effect of localized dynamic surface pre-heating in laser cladding od stellite 1. Surf Coat Tech. 2010;204:3911-9.

24. Tao Y, Li J, Lu Y, Hu L. Resudual stress distribution in different depths of $\mathrm{TiNi} / \mathrm{Ti}_{2} \mathrm{Ni}$-based laser clad coating prepared at different environmental temperatures. Trans Nonferrous Met Soc China. 2017;27:2043-54.

25. Huang C, Zhang Y, Vilar R, Shen J. Dry sliding wear behavior of laser clad TiVCrAlSi high enetropy alloy coatings on Ti6Al-4V substrate. Mater Des. 2012;41:338-43.

26. Tao Y, Li J, Lv Y, Hu L. Effect of heat treatment on residual stress and wear behaviors of the $\mathrm{TiNi} / \mathrm{Ti}_{2} \mathrm{Ni}$ based laser cladding composite coatings. Opt Laser Technol. 2017;97:379-89.

27. Fischer M, Laheurte P, Acquier P, Joguet D, Peltier L, Petithory $\mathrm{T}$, et al. Synthesis and characterization of Ti-27.5Nb alloy made by Clad $\AA$ additive manufacturing process for biomedical applications. Mater Sci Eng C. 2017;75:341-8.

28. Sun D, Gu D, Lin K, Ma J, Chen W, Huang J, et al. Selective laser melting of titanium parts: influence of laser process parameters on macro- and microstructures and tensile property. Powder Technol. 2019;342:371-9.

29. Rabadia CD, Liu YJ. 1. Wang, H. Sun, L.C. Zhang, Laves phase precipitation in Ti-Zr-Fe-Cr alloys with high strength and large plasticity. Mater Des. 2018;154:228-38.

30. Liu ZG, Wang X, Wang XP, Zhang CJ, Chai LH, Chen YY. Microstructural investigation of a rapidly solidified Ti-Zr-FeSi-Sn-Nb alloy. J Alloys Compd. 2010;504S:S480-2.

31. Zhao GH, Ketov SV, Jiang J, Mao H, Borgenstam A, LuizguineLuzgin DV. New beta-type Ti-Fe-Sn-Nb alloys with superior mechanical strength. Mater Sci Eng A. 2017;705:348-51.

32. Zhao G, Ketov SV, Mao H, Borgenstam A, Louzguine-Luzgin DV. Ti-Fe-Sn-Nb hypoeutectic alloys with superb yield strength and significant strain-hardening. Scr Mater. 2017;135:59-62.

33. Nabhani M, Razavi RS, Barekat M. Corrosion study of laser cladded Ti-6Al-4V alloy in different corrosive environments. Eng Fail Anal. 2019;97:234-41.

34. Jiang YQ, Li J, Juan YF, Lu ZJ, Jia WL. Evolution in microstructure and corrosion behavior of $\mathrm{AlCoCr}_{x} \mathrm{FeNi}$ high entropy alloy coatings fabricated by laser cladding. J Alloys Compd. 2019;775:1-14. 